\title{
Highly Transparent Indium Oxide Doped ZnO Spreading Layer for GaN Based Light Emitting Diodes
}

\author{
Jae-Hong $\operatorname{Lim}^{\dagger}$ and Seong-Ju Park* \\ Department of Chemical \& Environmental Engineering, University of California, Riverside, California 92521 \\ *Department of Materials Science and Engineering, Gwangju Institute of Science and Technology, \\ Gwangju 500-712, Korea
}

(Received June 17, 2009 : Received in revised form August 4, 2009 : Accepted August 10, 2009)

\begin{abstract}
This study develops a highly transparent ohmic contact scheme using indium oxide doped $\mathrm{ZnO}$ (IZO) as a current spreading layer for $p$-GaN in order to increase the optical output power of nitride-based lightemitting diodes (LEDs). IZO based contact layers of IZO, Ni/IZO, and NiO/IZO were prepared by e-beam evaporation, followed by a post-deposition annealing. The transmittances of the IZO based contact layers were in excess of $80 \%$ throughout the visible region of the spectrum. Specific contact resistances of $3.4 \times 10^{-4}$, $1.2 \times 10^{-4}, 9.2 \times 0^{-5}$, and $3.6 \times 10^{-5} \Omega \cdot \mathrm{cm}^{2}$ for IZO, Ni/Au, Ni/IZO, and NiO/IZO, respectively were obtained. The forward voltage and the optical output power of GaN LED with a NiO/IZO ohmic contact was $0.15 \mathrm{~V}$ lower and was increased by $38.9 \%$, respectively, at a forward current of $20 \mathrm{~mA}$ compared to that of a standard GaN LED with an Ni/Au ohmic contact due to its high transparency, low contact resistance, and uniform current spreading.
\end{abstract}

Key words LED, GaN, ZnO, Ni, NiO.

\section{Introduction}

$\mathrm{GaN}$ and related compounds are attractive materials for use in optoelectronic devices in the blue and ultraviolet spectral region. ${ }^{1-3)}$ However, their high contact resistance and low transmission efficiency reduce the overall performance of such electronic and optical devices. The fabrication of high-quality ohmic contacts with low resistance, high thermal stability, and high transparency, is of particular technological importance in optical device applications. Typically, an oxidized Ni/Au thin film is commonly used as an ohmic contact to $p$-GaN. ${ }^{4}$ However, as the total thickness of the $\mathrm{Ni} / \mathrm{Au}$ contacts increases for uniform current spreading, the light transmission efficiency decreases leading to LEDs with a low light extraction efficiency. Therefore, there is a great need to improve the extraction efficiency and current spreading of GaN based LEDs. Recently, indium tin oxide (ITO) was used as a $p$-contact layer, in attempt to overcome this problem and it is noteworthy that a $\mathrm{Ni}$ interlayer between the ITO and $p$ GaN lowered the contact resistance of $\mathrm{Ni} / \mathrm{ITO}$ on $p$-GaN substantially, via the formation of a $\mathrm{NiO}$ phase. ${ }^{6)}$ The indium oxide doped $\mathrm{ZnO}$ (IZO) is also a conducting oxide

Corresponding author

E-Mail : limjh92@gmail.com(J. -H. Lim) which has a high transparency in the visible spectral region, a high electrical conductivity, and a high work function. $^{7-8)}$ In this study, an indium oxide doped $\mathrm{ZnO}$ (IZO) based contact scheme was used as a transparent $p$ contact material with low contact resistance. The optical and electrical properties of GaN based LEDs using IZO based contact layers were investigated. The findings show that the forward voltage of the LED with NiO/IZO measured at a $20 \mathrm{~mA}$ injection current was decreased by $0.15 \mathrm{~V}$, compared to that of an LED with $\mathrm{Ni} / \mathrm{Au}$. In addition, the optical output power of an LED with a NiO/IZO film was $1.32 \mathrm{~mW}$, an increase of $38.9 \%$ at $20 \mathrm{~mA}$, compared to that of an LED with a $\mathrm{Ni} / \mathrm{Au}$ layer.

\section{Experimental Procedure}

The LED structure used in this study consisted of a GaN nucleation layer, a Si-doped $n$-GaN layer, five periods of InGaN/GaN MQWs as an active layer, and a Mg-doped $p$-GaN as a capping layer. The samples were grown on a $c$-plane sapphire substrate using metalorganic chemical vapor deposition (MOCVD) in a rotating disk reactor $\left(\right.$ Emcore $\left.\mathrm{D} 125^{\mathrm{TM}}\right)$. A detailed description of the procedures used have been reported elsewhere. ${ }^{9)}$ In order to investigate the effect of an IZO transparent ohmic contact layer on the electrical and optical performance of LEDs, LED 
chips using transparent IZO based contact layers were fabricated. The surface of the $p$-type GaN layer was partially etched using an inductively coupled $\mathrm{CH}_{4} / \mathrm{Cl}_{2} / \mathrm{H}_{2} / \mathrm{Ar}$ plasma until the $n$-GaN layer was exposed for a $n$-type electrode pad. Highly transparent IZO based ohmic contact layers were deposited on the $p$-GaN layer as a current spreading layer via e-beam evaporation technique using a $\mathrm{ZnO}$ source containing $3 \mathrm{wt} \% \mathrm{In}_{2} \mathrm{O}_{3}$. To investigate the effect of interlayers on contact resistance, a $\mathrm{Ni}$ or $\mathrm{NiO}$ layer was inserted between the IZO and the $p$-GaN films. The annealing conditions were $600{ }^{\circ} \mathrm{C}$ for $5 \mathrm{~min}$ for the IZO contact and $500{ }^{\circ} \mathrm{C}$ for $1 \mathrm{~min}$ for interlayer inserted IZO contacts under a nitrogen ambient. Ti/Al $(30 \mathrm{~nm} / 80 \mathrm{~nm})$ metallization was then employed as an $n$-type ohmic contact and a $p$-type electrode pad. $\mathrm{Ni} / \mathrm{Au}(3 \mathrm{~nm} / 5 \mathrm{~nm})$ was deposited as a current spreading layer on $p$-type $\mathrm{GaN}$ for the reference LED. These contacts were patterned using a standard metal lift-off technique. Prior to deposition, the samples were cleaned in a buffered oxide etchant (BOE) solution. This cleaning process was found to greatly enhance the adhesion of the contact layers by removing oxides from the surfaces of the exposed GaN. A detailed descriptions of the procedures used in the device fabrication has been reported elsewhere. ${ }^{10)}$ For the electrical and optical characteristics of the MQW LED, currentvoltage $(I-V)$ and electroluminescence (EL) measurements were performed at room temperature.

\section{Results and discussions}

In order to investigate the light transmittance of an annealed IZO layer in the visible region, the light transmittance spectra of IZO $(200 \mathrm{~nm}), \mathrm{Ni} / \mathrm{IZO}(5 / 200 \mathrm{~nm})$, and $\mathrm{NiO} / \mathrm{IZO}(5 / 200 \mathrm{~nm})$ films were measured by means of a UV/VIS spectrometer and the results are shown in Fig. 1. A GaN grown sapphire substrate was used as a reference sample to calibrate the light transmittance measurement. As shown in Fig. 1, light transmittance values are 86.5\% for IZO, $81.3 \%$ for $\mathrm{Ni} / \mathrm{IZO}$, and $81.1 \%$ for $\mathrm{NiO} / \mathrm{IZO}$ at a wavelength of $450 \mathrm{~nm}$. The transmittances of Ni/IZO and $\mathrm{NiO} / \mathrm{IZO}$ are lower than that of IZO due to the absorption of light by the $\mathrm{Ni}$ and $\mathrm{NiO}$ interlayers. The large transmittances, in excess of $80 \%$, suggest that the IZO based contact films would be suitable to serve as transparent contact layers for $p$-GaN. The specific contact resistance was measured using the circular transmission line method (c-TLM) patterns. ${ }^{11)}$ A specific contact resistance of $3.4 \times 10^{-4}$,

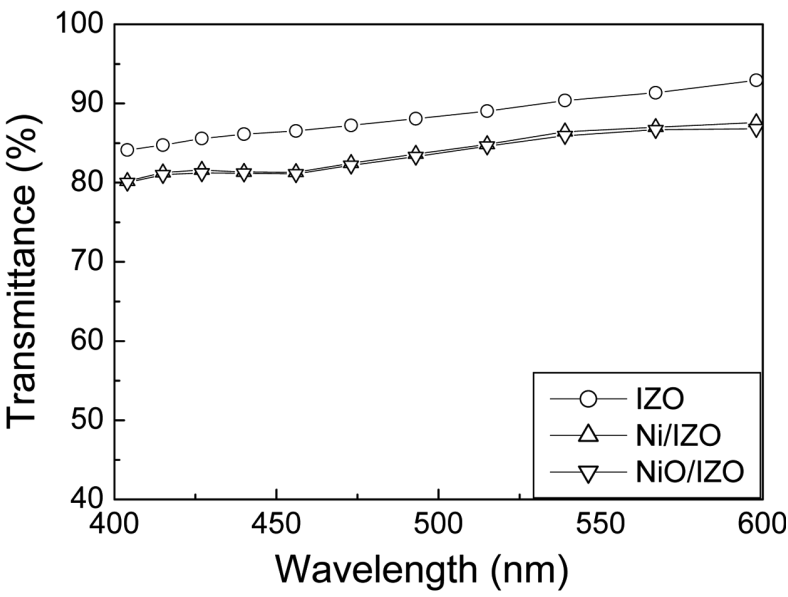

Fig. 1. Light transmission spectra of annealed IZO $(200 \mathrm{~nm})$, $\mathrm{Ni} / \mathrm{IZO}(5 / 200 \mathrm{~nm}), \mathrm{NiO} / \mathrm{IZO}(5 / 200 \mathrm{~nm})$ contacts on $p$-GaN films.

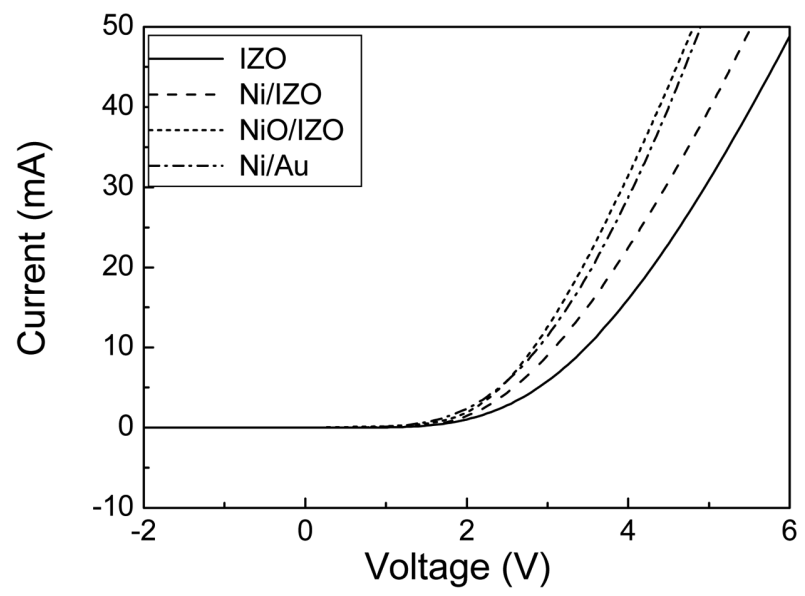

Fig. 2. $I-V$ curves for LEDs using IZO $(200 \mathrm{~nm}), \mathrm{Ni} / \mathrm{IZO}(5 /$ $200 \mathrm{~nm}), \mathrm{NiO} / \mathrm{IZO}(5 / 200 \mathrm{~nm})$, and $\mathrm{Ni} / \mathrm{Au}(5 / 8 \mathrm{~nm})$ layers as the transparent layer.

$1.2 \times 10^{-4}, 9.2 \times 10^{-5}$, and $3.6 \times 10^{-5} \Omega \cdot \mathrm{cm}^{2}$ for $\mathrm{IZO}, \mathrm{Ni} / \mathrm{Au}$, $\mathrm{Ni} / \mathrm{IZO}$, and $\mathrm{NiO} / \mathrm{IZO}$, respectively was obtained. The improvement in contact resistance observed in the annealed IZO with a $\mathrm{NiO}$ interlayer on $p$-GaN can be attributed to the formation of a highly conductive semiconductor layer of $p$ - $\mathrm{NiO}$ at the interface between the IZO and $p-\mathrm{GaN} .^{12-13)}$

To investigate the effect of various interlayers on the hole injection and current spreading, LEDs were fabricated with a dimension of $300 \times 300 \mu \mathrm{m}$. Fig. 2 shows the $I-V$ characteristic of LEDs with different $p$-contacts. The forward voltage, measured at an injection current of $20 \mathrm{~mA}$, is $3.55 \mathrm{~V}, 3.85 \mathrm{~V}, 3.40 \mathrm{~V}$, and $4.30 \mathrm{~V}$ for the LEDs with $\mathrm{Ni} / \mathrm{Au}, \mathrm{Ni} / \mathrm{IZO}, \mathrm{NiO} / \mathrm{IZO}$, and IZO film, respectively, as shown in Fig. 2. The increase in the operation voltage of the LED with an IZO $p$-contact can be attributed to the poor ohmic contact properties of IZO on $p-\mathrm{GaN}$ compared 


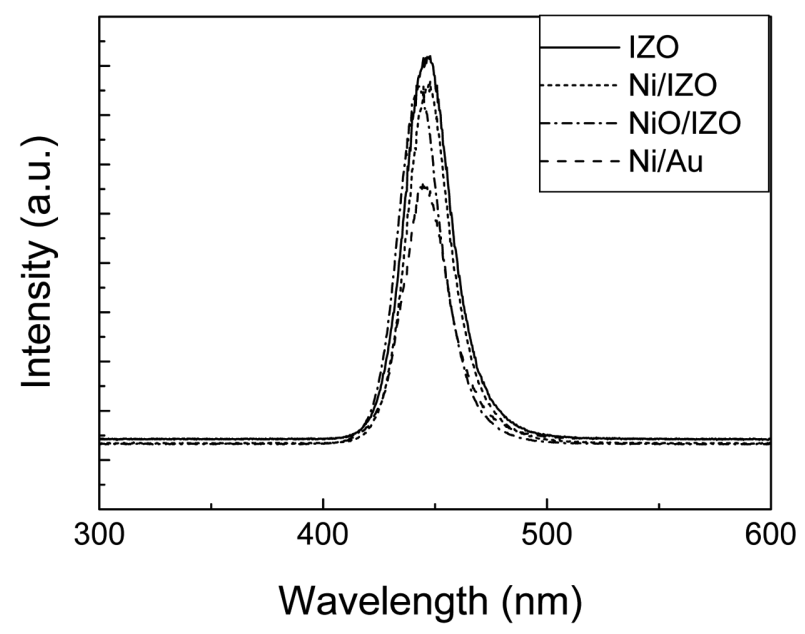

Fig. 3. EL spectra of LEDs using IZO (200 nm), Ni/IZO (5/ $200 \mathrm{~nm}), \mathrm{NiO} / \mathrm{IZO}(5 / 200 \mathrm{~nm})$, and $\mathrm{Ni} / \mathrm{Au}(5 / 8 \mathrm{~nm})$ layers as a transparent layer at an injection current of $20 \mathrm{~mA}$ at room temperature.

to that of an LED with a $\mathrm{Ni} / \mathrm{Au} p$-contact. The contact resistance, however, was reduced, when a $\mathrm{Ni}$ or $\mathrm{NiO}$ interlayer was inserted between the IZO and $p$-GaN film. The forward voltage of LED with a NiO/IZO ohmic contact layer was decreased by $0.15 \mathrm{~V}$ compared to that of an LED with a Ni/Au contact. This indicates that a $\mathrm{NiO} / \mathrm{IZO}$ layer represents a promising contact scheme for use in high efficient LEDs because of its contact resistance, uniform current spreading, and high transparency.

Fig. 3 shows the EL spectra of LEDs with IZO based contact schemes and a Ni/Au contact for use in a comparative study. The EL peaks of the LEDs were all located at $450 \mathrm{~nm}$. However, the LEDs with IZO based $p$-contact schemes showed a stronger EL intensity than that for an LED with a Ni/Au $p$-contact layer. To further investigate the influence of IZO based contact layers on the optical output performance of an LED chip, the optical output power was measured using a calibrated $\mathrm{Si}$ photodiode. Fig. 4 shows the optical output power of LEDs with different ohmic contacts as a function of injection current. Unpackaged LED chips were used in this measurement. The optical output power of the LED with an IZO $p$ contact exceeded that of an LED with a Ni/Au contact to $p$-GaN. The optical output powers of the LEDs were $1.45 \mathrm{~mW}$ for IZO, $1.38 \mathrm{~mW}$ for $\mathrm{Ni} / \mathrm{IZO}, 1.32 \mathrm{~mW}$ for $\mathrm{NiO} / \mathrm{IZO}$, and $0.95 \mathrm{~mW}$ for $\mathrm{Ni} / \mathrm{Au}$ at an injection current of $20 \mathrm{~mA}$, and were increased by $52.6 \%$ for IZO, $45.2 \%$ for $\mathrm{Ni} / \mathrm{IZO}$, and $38.9 \%$ for $\mathrm{NiO} / \mathrm{IZO}$ compared to that of an LED with a Ni/Au layer. However, the operating voltages of an LED with IZO and Ni/IZO at $20 \mathrm{~mA}$ were

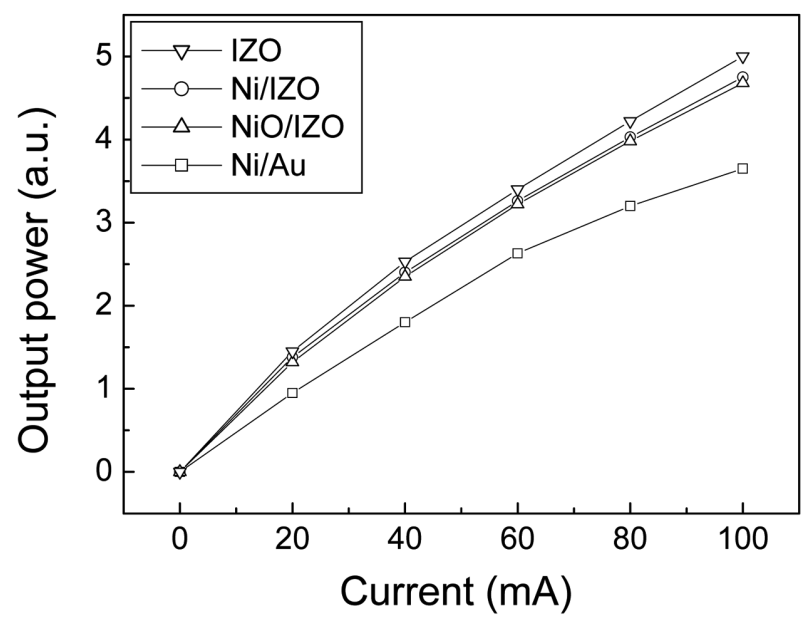

Fig. 4. Optical output power of LEDs using IZO (200 nm), Ni/ IZO $(5 / 200 \mathrm{~nm}), \mathrm{NiO} / \mathrm{IZO}(5 / 200 \mathrm{~nm})$, and $\mathrm{Ni} / \mathrm{Au}(5 / 8 \mathrm{~nm})$ layers as a transparent layer as a function of a forward injection current at room temperature.

higher than that of an LED with NiO/IZO. Therefore, the $\mathrm{NiO} / \mathrm{IZO} p$-contact showed the highest wall plug efficiency (optical output power/electrical input power). The application of transparent conducting Al-Doped $\mathrm{ZnO}$ films to GaN LED shows 30\% increase of the optical output power, however, it gives much increase of the operation voltage. 14 The significant increase in optical output power of LEDs with IZO based contacts can be attributed to its high transparency, low contact resistance, and uniform current spreading of IZO compared to that of a $\mathrm{Ni} / \mathrm{Au}$ film as a transparent $p$-contact layer.

\section{Conclusions}

The effect of transparent IZO based contact layers IZO, $\mathrm{Ni} / \mathrm{IZO}$, and $\mathrm{NiO} / \mathrm{IZO}$ on the electrical and optical performance of $\mathrm{GaN}$ based LEDs were investigated. The forward voltage of an LED with $\mathrm{NiO} / \mathrm{IZO}$ contact was decreased by $0.15 \mathrm{~V}$ and the optical output power was increased by $38.9 \%$ compared to that of the LED with a $\mathrm{Ni} / \mathrm{Au}$ contact. This result can be attributed to the properties of $\mathrm{NiO} / \mathrm{IZO}$ film, such as its low contact resistance, high transparency, and uniform current spreading compared to those of a $\mathrm{Ni}$ / Au layer.

\section{References}

1. S. Nakamura, M. Senoh, S. Nagahama, N. Iwasa, T. Yamada, T. Matsushita, H. Kiyoku, Y. Sugimoto, T. Kozaki, H. Umemoto, M. Sano and K. Cho, Appl. Phys. Lett., 72(16), 2014 (1998). 
2. S. Nakamura, T. Mukai and M. Senoh, Appl. Phys. Lett., 64(13), 1687 (1994).

3. S. Nakamura, G. Fasol, The Blue Laser Diode, Springer, Berlin, (1997).

4. J. -K. Ho, C. -S. Jong, C. -N. Huang, C. -Y. Chen, C. C. Chiu and K.-K. Shih, Appl. Phys. Lett., 74(9), 1275 (1999).

5. J. -K. Ho, C. -S. Jong, C. C. Chiu, C. -N. Huang, K. -K. Shih, L. -C. Chen, F. -R. Chen and J. -J. Kai, J., Appl. Phys., 86(8), 4491 (1999).

6. R. -H. Horng, D. -S. Wuu, Y. -C. Lien and W. -H. Lan, Appl. Phys. Lett., 79(18), 2925 (2001).

7. T. Minami, T. Miyata and T. Yamamoto, Surf. Coat. Tech., 108(1), 583 (1998).

8. T. Minami, T. Kakumu and S. Takata, J. Vac. Sci. Technol. A, 14(3), 1704 (1996).
9. D. -J. Kim, Y. -T. Moon, K. -M. Song and S. J. Park, Jpn. J. Appl. Phys. Part 1, 40(5A), 3085 (2001).

10. C. Huh, S. W. Kim, H. S. Kim, H. M. Kim, H. Hwang and S. J. Park, Appl. Phys. Lett., 78(12), 1766 (2001).

11. C. Huh, S. W. Kim, H. M. Kim, D. J. Kim and S. J. Park, Appl. Phys. Lett., 78(13), 1942 (2001).

12. J. -H. Lim, D. -K. Hwang, H. -S. Kim, J. -Y. Oh, J. -H. Yang, R. Navamathavan and S. J. Park, Appl. Phys. Lett., 85(25), 6191 (2004).

13. J. -H. Lim, D. -K. Hwang, H. -S. Kim, J. -Y. Oh, J. -H. Yang, R. Navamathavan and S. J. Park, J. Electrochem. Soc., 152(6), G491 (2005).

14. S. H. Lee, Y. M. Yu, T. H. Kim and S. -Y. Jeong, J. Kor. Phys. Soc., 51(2) S79 (2007). 